\title{
Effects of hydrostatic distention on in vitro vasoreactivity of radial artery conduits
}

\author{
Chee Fui Chong, BSc, FRCS ${ }^{a}$ \\ Paul J. L. Ong, MB, BChir, MRCP \\ Neil Moat, MS, FRCS ${ }^{a}$ \\ Peter Collins, MD, FRCP
}

From the Department of Cardiothoracic Surgery, Royal Brompton and Harefield NHS Trust, London, United Kingdom, ${ }^{\mathrm{a}}$ and the Department of Cardiac Medicine, National Heart and Lung Institute at Imperial College of Science, Technology and Medicine, London, United Kingdom. ${ }^{\text {b }}$

Supported by the Kate Weeks Research Fellowship, Royal College of Surgeons, England, and a Clinical Research Committee Fellowship, Royal Brompton and Harefield NHS Trust.

Received for publication Nov 24, 2003; revisions requested Feb 2, 2004; revisions received Feb 24, 2004; accepted for publication April 1, 2004.

Address for reprints: Chee Fui Chong, BSc, FRCS, Department of Cardiac, Thoracic and Vascular Surgery, National University Hospital, 5 Lower Kent Ridge Rd, Singapore 119074 (E-mail: chong_chee_fui@ hotmail.com).

J Thorac Cardiovasc Surg 2004;128:609-14 $0022-5223 / \$ 30.00$

Copyright () 2004 by The American Association for Thoracic Surgery

doi:10.1016/j.jtcvs.2004.02.041
Background: Surgical preparation of coronary conduits may affect early and longterm patency through endothelial and smooth muscle injury. We investigated the effect of hydrostatic distention on the in vitro endothelial function and contractile properties of the human radial artery.

Methods: Human radial arteries were harvested and distended to physiologic pressure or suprasystemic pressure $(>300 \mathrm{~mm} \mathrm{Hg}$ ) by using heparinized whole blood for 2 minutes. Distal segments were retrieved and prepared into 3-mm rings. These were mounted and stretched to optimum resting tension in oxygenated Krebs solution at $37^{\circ} \mathrm{C}$. Contraction responses to potassium, norepinephrine, and serotonin and relaxation responses to acetylcholine and nitroprusside were evaluated. Undistended radial artery segments were used as controls.

Results: Vasocontraction to all 3 contractile agonists was significantly different between groups. The radial artery subjected to suprasystemic pressure distention achieved the lowest percentage of maximum contraction (potassium, $P<.001$; norepinephrine, $P<.05$; serotonin, $P<.05$ ). The median effective concentration was also significantly reduced in this group, indicating increased sensitivity to all 3 agonists. Receptor-mediated contractility was significantly reduced in both distended groups when compared with controls. Relaxation to acetylcholine and nitroprusside was significantly reduced in the suprasystemic pressure-distended group, which had a tendency to vasospasm when exposed to a physiologic concentration of acetylcholine $\left(10^{-6} \mathrm{~mol} / \mathrm{L}\right)$. Median effective concentrations for both acetylcholine and nitroprusside were not different between groups.

Conclusions: Excessive distention of the radial artery leads to a significant reduction in vasoreactivity, which may be attributed to a disruption of the vascular endothelium and media, with a propensity for graft spasm with exposure to acetylcholine.

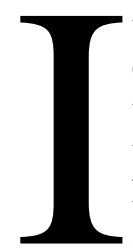

$t$ is generally accepted that endothelial and medial injury resulting from excessive distention of coronary conduits is detrimental to the longevity of the graft. ${ }^{1-3}$ Mechanical dilation with metal probes may have contributed to the poor early patency results in radial artery (RA) grafts. ${ }^{4,5}$ A change in harvesting techniques by Acar and associates, ${ }^{5}$ with avoidance of distention and the use of calcium channel blockers to relieve vasospasm, led to an improvement in early patency.

The effect of excessive hydrostatic distention on arterial conduits has been previously investigated with internal thoracic artery (ITA) grafts. ${ }^{2,6}$ Cooper and colleagues $^{6}$ reported a significant reduction in vasoreactivity of the ITA caused by damage of the media layer after excessive hydrostatic distention. Unlike the ITA, which is an elastic artery, the RA is a muscular artery with much thicker media. ${ }^{7}$ Therefore, excessive hydrostatic distention to suprasystemic pressure may have a more profound effect on the media and its vasoreactivity. This study investigated the 
effect of hydrostatic distention at physiologic and suprasystemic pressures on RA vasoreactivity.

\section{Materials and Methods Protocol}

Human RA segments were obtained from patients undergoing coronary artery bypass grafting surgery with the RA as a conduit. These were carefully harvested, and side branches were ligated with Ligaclips (Ethicon Endo-Surgery, Inc, Cincinnati, Ohio), as previously described by Reyes and colleagues. ${ }^{8}$ Once disconnected from the forearm, the RA was clamped at the distal end with a DeBakey atraumatic bulldog clamp. The proximal end was cannulated and injected with heparinized whole blood to check for leaks. The distention pressure was maintained at $206 \pm 6 \mathrm{~mm} \mathrm{Hg}$ for 2 minutes in the physiologic pressure distention group. At this pressure, there was no visible permanent change to the caliber of the RA. For the suprasystemic pressure distention group, the RA was distended at $336 \pm 10 \mathrm{~mm} \mathrm{Hg}$ (which is well above systemic pressure), and this resulted in a visible permanent change in the RA diameter. The distention pressure was monitored with a manometer line connected to a Hewlett-Packard (Palo Alto, Calif) Viridia Critical Care system. Undistended RA segments were used as controls for comparison.

The distal 1.5 - to $2-\mathrm{cm}$ segments of the artery were then collected for the in vitro vasoreactivity studies. The use of discarded distal segments of RA was approved by the Royal Brompton Hospital Ethics Committee, and written consent was obtained from all patients.

\section{Preparation of RA Segments}

RA segments were immediately transferred to the laboratory in cold $\left(4^{\circ} \mathrm{C}\right)$ oxygenated Krebs solution (composition [mmol/L]: $\mathrm{Na}^{+} 144, \mathrm{~K}^{+} 5.9, \mathrm{Ca}^{2+} 2.5, \mathrm{Mg}^{2+} 1.2, \mathrm{Cl}^{-} 128.7, \mathrm{HCO}_{3}{ }^{-} 25$, $\mathrm{SO}_{4}{ }^{2-} 1.2, \mathrm{H}_{2} \mathrm{PO}_{4}{ }^{-} 1.2$, and glucose 11). The RA segments were dissected free of surrounding satellite veins and connective tissue and cut into 3-mm rings.

\section{Organ Bath Procedure}

RA rings were mounted on specially designed wire hooks and attached to a strain gauge in $10-\mathrm{mL}$ jacketed organ baths containing oxygenated Krebs solution at $37^{\circ} \mathrm{C}$. The rings were normalized to resting tension by using the length-tension curves described previously. ${ }^{9}$ After this normalization procedure, the RA rings were equilibrated for 1 hour. Each ring was precontracted with 100 mmol of potassium before the vasoreactivity study. The organ bath Krebs solution was changed every 20 minutes. Between contraction or relaxation studies, the rings were rinsed regularly at 20minute intervals and allowed to equilibrate to baseline resting tension. Each RA ring was subjected to cumulative doses of contractile or relaxation agents in random order.

\section{Contraction}

Cumulative contraction curves to potassium (10-80 mmol/L), norepinephrine $\left(10^{-8}-10^{-4.5} \mathrm{~mol} / \mathrm{L}\right)$, and serotonin $\left(10^{-8}-10^{-4.5}\right.$ $\mathrm{mol} / \mathrm{L})$ were performed to assess voltage-mediated and receptormediated contraction. Median effective concentrations $\left(\mathrm{EC}_{50}\right.$; concentration at $50 \%$ maximum contraction) were calculated.

\section{Relaxation}

$\mathrm{RA}$ rings were precontracted with the potassium $\mathrm{EC}_{50}$. When the contraction reached a plateau or after 7 minutes, cumulative relaxation curves to each vasodilator agent were constructed. Endothelium-dependent relaxation to acetylcholine $\left(10^{-8}-10^{-4.5}\right.$ $\mathrm{mol} / \mathrm{L}$ ) and endothelium-independent relaxation to sodium nitroprusside $\left(10^{-10}-10^{-6.5} \mathrm{~mol} / \mathrm{L}\right)$ were assessed. Preliminary studies using a single dose of acetylcholine $10^{-6.0} \mathrm{~mol} / \mathrm{L}$ were also conducted before cumulative studies. All drugs were obtained from Sigma-Aldrich Co Ltd (Poole, Dorset, United Kingdom).

\section{Data Analysis}

Results are expressed as mean \pm SEM of the maximal contraction and relaxation achieved at each concentration and were plotted on cumulative curves. $\mathrm{EC}_{50}$ values were calculated to assess sensitivity. Results were analyzed with 1-way analysis of variance (Microsoft Excel; Microsoft, Redmond, Wash). Post hoc analysis was performed by Student-Newman-Keuls tests for multiple comparisons.

\section{Results}

\section{Voltage-Dependent Contraction to Potassium}

The maximum contraction achieved by rings distended to suprasystemic pressure $(\mathrm{n}=6)$ was significantly $(P<.05)$ and consistently reduced when compared with both controls $(n=7)$ and physiologic pressure-distended rings $(n=12)$ for concentrations greater than $20 \mathrm{mmol}$ of potassium, as shown in Figure 1, A. There was no difference in maximal contraction achieved between control rings and physiologic pressure-distended rings.

\section{Receptor-Mediated Contraction}

There was a significant difference in the maximum contraction achieved to norepinephrine $\left(>10^{-7} \mathrm{~mol} / \mathrm{L}\right)$ among groups (control, $\mathrm{n}=6$; physiologic, $\mathrm{n}=7$; suprasystemic, $\mathrm{n}=5 ; P<.001 ;$ Figure $1, B$ and $C$ ). RA rings distended to physiologic pressures achieved $40 \%(P<.05)$ less in magnitude, whereas those distended to suprasystemic pressure showed an $80 \%(P<.05)$ reduction in the magnitude of contraction compared with control rings, as shown in Figure $1, B$. There were no differences in maximum contraction between physiologic and suprasystemic pressure-distended RA rings for concentrations less than $10^{-5.5} \mathrm{~mol} / \mathrm{L}$.

Similarly, there was a significant difference among groups in the maximum contraction to serotonin (control, $\mathrm{n}$ $=3$; physiologic, $\mathrm{n}=7$; suprasystemic, $\mathrm{n}=5 ; P<.001$ ). At serotonin concentrations greater than $10^{-7} \mathrm{~mol} / \mathrm{L}$, both distended groups achieved a significantly lower maximum contraction $(P<.01)$, as shown in Figure 1, $C$.

The $\mathrm{EC}_{50}$ values for all 3 contractile agonists for RA rings subjected to suprasystemic pressure distention were significantly reduced, indicating an increased sensitivity when compared with control and physiologic groups (Table 1). 


\section{Endothelium-Dependent Relaxation}

A significant difference in endothelium-dependent relaxation was achieved at all concentrations of acetylcholine within groups (control, $\mathrm{n}=3$; physiologic, $\mathrm{n}=6$; suprasystemic, $\mathrm{n}=4$; Figure 2, A). RA rings subjected to suprasystemic pressure distention achieved a significantly reduced maximal percentage of relaxation at all concentrations of acetylcholine compared with controls $(P<.01)$ and at concentrations greater than $10^{-6} \mathrm{~mol} / \mathrm{L}$ when compared with the physiologic pressure-distended group $(P<.05)$. More important, at such physiologic concentrations, acetylcholine caused cyclical contraction or vasospasm of significant magnitude in suprasystemic pressure-distended RA rings, and this was not seen in physiologic pressure-distended or control RA rings (Figure 3). At physiologic concentrations of acetylcholine $\left(>10^{-6} \mathrm{~mol} / \mathrm{L}\right)$, the maximum percentage of relaxation achieved by physiologic pressuredistended RA rings was not significantly different from that of control rings.

\section{Endothelium-Independent Relaxation}

The maximum endothelium-independent relaxation achieved with nitroprusside ranged from $48 \%$ to $94 \%$ (control, $\mathrm{n}=3$; physiologic, $\mathrm{n}=6$; suprasystemic, $\mathrm{n}=3$; Figure 2, $B$ ) and was significantly different between groups for concentrations greater than $10^{-8} \mathrm{~mol} / \mathrm{L}$. The suprasystemic pressure-distended RA groups achieved a significantly lower percentage of relaxation among groups $(P<$ $.05)$. There was no difference in relaxation between distended groups. The $\mathrm{EC}_{50}$ values for acetylcholine and nitroprusside were not significantly different between groups (Table 1).

\section{Discussion}

RA is a class 3 muscular artery and is extremely prone to vasospasm during harvesting. ${ }^{7}$ This vasospasm results in a change in mechanical properties, leading to increased stiffness and reduced distensibility. ${ }^{10}$ Various pharmacologic agents have been used to overcome this, such as calcium channel blockers, ${ }^{5,11,12}$ nitrates, ${ }^{13}$ papaverine, ${ }^{11,14-18}$ and, more recently, phenoxybenzamine. ${ }^{19}$ Improvements in surgical harvesting techniques and the use of gentle hydrostatic distention have also helped to relieve RA vasospasm. ${ }^{20}$ Our results indicate that progressive increases in hydrostatic distention pressures have a cumulative effect on the vasoreactivity of the RA conduit.

By increasing the distention pressure, the RA resisted distention until a pressure was reached whereby the arterial wall yielded and an irreversible increase in vessel diameter was seen. This was the yield pressure, which averaged approximately $336 \pm 10 \mathrm{~mm} \mathrm{Hg}$ for the RA. This pressure was much higher than that reported for the ITA $(280 \mathrm{~mm}$
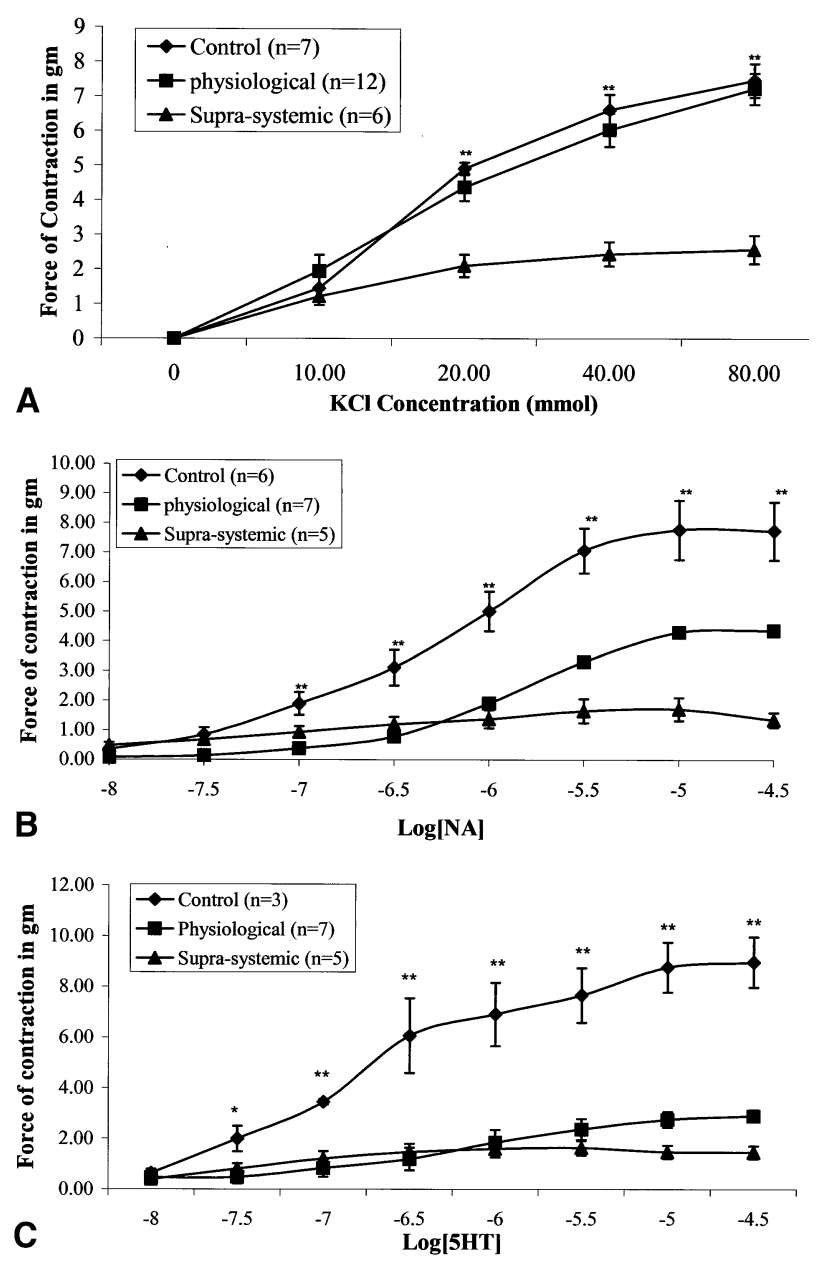

Figure 1. A, Cumulative contraction curves to $\mathrm{KCl}$ of $\mathrm{RA}$ rings distended hydrostatically to physiologic pressure ( $\square$ ), to suprasystemic pressure $(\Delta)$, and control (no distention; $\diamond$ ). There was a significant difference between groups in the absolute maximum contraction achieved for concentrations greater than $20 \mathrm{mmol}$ of $\mathrm{KCI}\left({ }^{* *} \boldsymbol{P}<.001\right)$. RA rings distended at suprasystemic pressure achieved significantly lower absolute maximum contraction compared with controls and physiologically distended rings $(P<.05)$. $B$, Cumulative contraction curves to NA of RA rings distended hydrostatically to physiologic pressure ( $\square$ ), to suprasystemic pressure $(\boldsymbol{\Delta})$, and control (no distention; $\bullet$ ). There was a significant difference between groups in the absolute maximum contraction to NA (**P $<.001)$ : both distended groups achieved significantly lower absolute maximum contractions compared with controls $(P<.05)$. NA, Norepinephrine. C, Cumulative contraction curves to serotonin of $\mathrm{RA}$ rings distended hydrostatically to physiologic pressure $(\square)$, to suprasystemic pressure $(\Delta)$, and control (no distention; $\diamond$ ). There was a significant difference between groups in the absolute maximum contraction to serotonin $\left({ }^{*} \boldsymbol{P}<.05 ;{ }^{*} \boldsymbol{P}<.001\right)$ : both distended groups achieved significantly lower absolute maximum contraction compared with control rings at serotonin concentrations greater than $10^{-7}$ $\mathrm{mol} / \mathrm{L}(P<.01) .5 H T$, Serotonin. 
TABLE 1. $E C_{50}$ of RA rings distended at physiologic and suprasystemic pressures

\begin{tabular}{lccccc}
\hline & \multicolumn{4}{c}{ EC $_{\mathbf{5 0}}$} \\
\cline { 2 - 6 } RA rings & KCI & NE & Serotonin & ACh & SNP \\
\hline Control & $16.0 \pm 0.9$ & $-6.3 \pm 0.1$ & $-6.7 \pm 0.2$ & $-8.1 \pm 0.01$ & $-6.8 \pm 0.4$ \\
Physiologic distention & $17.4 \pm 1.6$ & $-5.1 \pm 0.9$ & $-6.1 \pm 0.2$ & $-7.3 \pm 0.3$ & $-5.7 \pm 0.3$ \\
Suprasystemic distention & $10.9 \pm 1.3$ & $-7.4 \pm 0.3$ & $-7.4 \pm 0.3$ & $-7.8 \pm 0.1$ & $-6.9 \pm 0.8$ \\
$P$ value & $<.05$ & $<.001$ & $<.05$ & .2 & .15 \\
\hline
\end{tabular}

$E C_{50}$, Median effective concentration; RA, radial artery; $N E$, norepinephrine; Ach, acetylcholine; SNP, sodium nitroprusside. There were significant differences in $\mathrm{EC}_{50}$ values of the 3 contractile agents, $\mathrm{KCl}, \mathrm{NE}$, and serotonin, within the groups. The significant difference was only present in $\mathrm{RA}$ rings distended to suprasystemic pressure as compared with controls and physiologically distended group, indicating increased sensitivity to all 3 contractile agonists. There was no significant difference, however, in $\mathrm{EC}_{50}$ values to ACh and SNP.
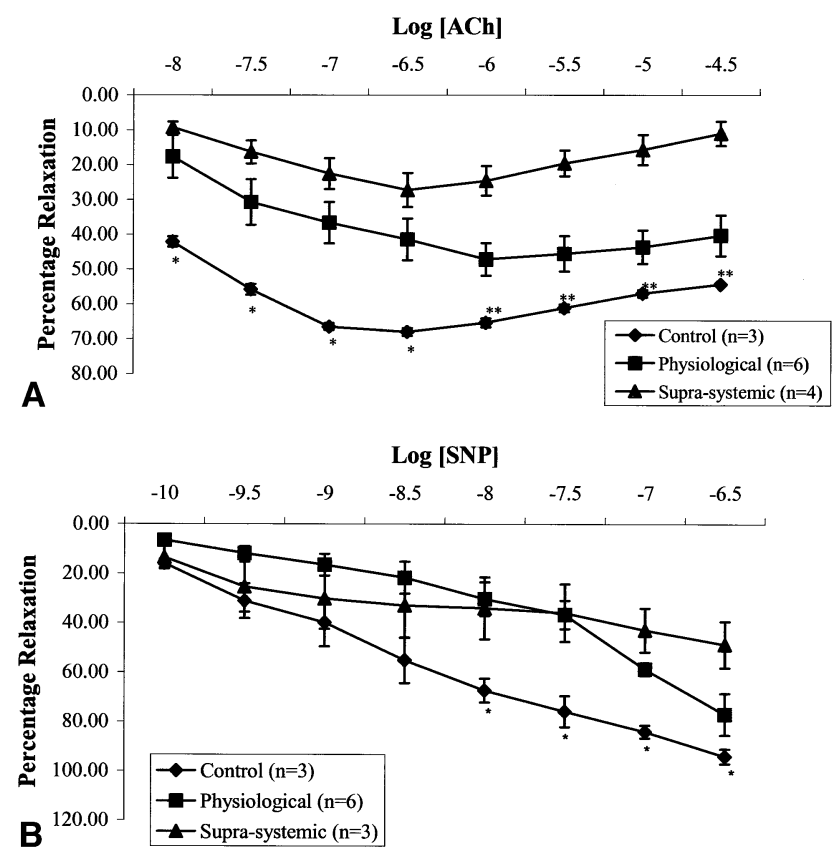

Figure 2. A, Cumulative relaxation curves to acetylcholine (ACh) of RA rings distended hydrostatically to physiologic pressure ( $\square$ ), to suprasystemic pressure $(\boldsymbol{\Delta})$, and not distended (controls; $\bullet$ ). There was a significant difference between groups $\left({ }^{*} P<.05\right)$. RA rings with suprasystemic pressure distention achieved the lowest percentage of relaxation ( $>50 \%$ loss of relaxation compared with controls [**P<.01]) for physiologic concentrations of ACh $10^{-6}$ to $10^{-4.5} \mathrm{~mol} / \mathrm{L}$ on posthoc analysis. B, Cumulative relaxation curves to sodium nitroprusside (SNP) of RA rings distended hydrostatically to physiologic pressure ( $\square$ ), to suprasystemic pressure ( $\Delta$ ), and not distended (controls; $\downarrow$ ). There was a significant difference between groups in maximum relaxation achieved at concentrations of SNP greater than $10^{-8} \mathrm{~mol} / \mathrm{L}$ ( $^{*} P<$ .05). RA rings with suprasystemic pressure distention achieved a significantly lower percentage of relaxation $(P<.05)$.

$\mathrm{Hg}$ ), possibly because the RA has a much thicker muscle medium than the ITA. ${ }^{2}$

RA rings subjected to suprasystemic pressure distention have reduced contraction (70\%-80\% loss of contraction) to
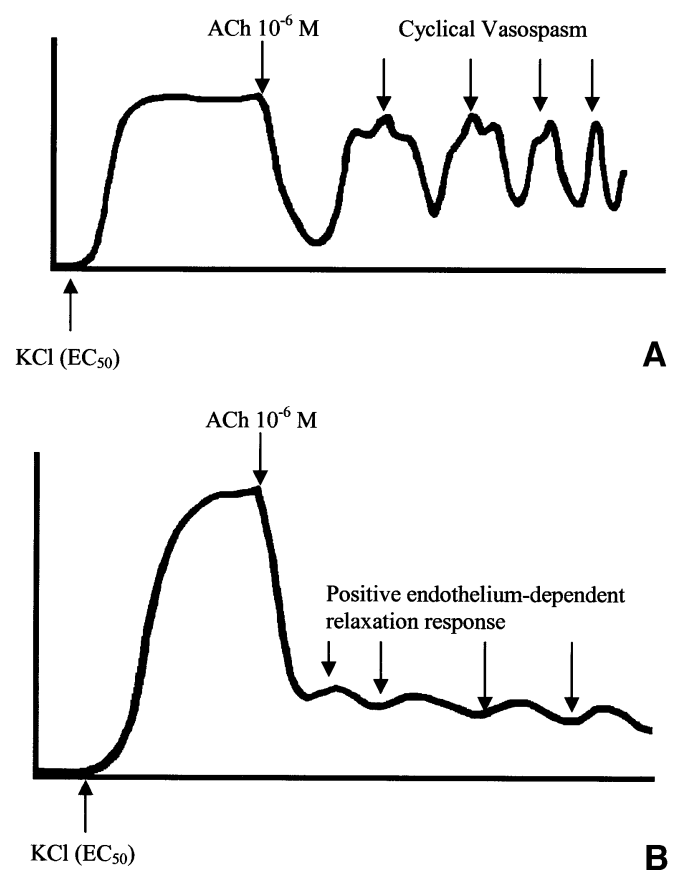

Figure 3. Vasorelaxation responses of $R A$ rings to acetylcholine $(A C h)$. The response to $A C h 10^{-6} \mathrm{~mol} / \mathrm{L}$ is shown in (A) RA distended to suprasystemic pressure $(359 \mathrm{~mm} \mathrm{Hg}$ ), showing a loss of endothelium-dependent relaxation, which was replaced by the cyclical vasoconstriction typical of vasospasm, indicating endothelium damage, and (B) RA exposed to systemic pressure distention ( $<200 \mathrm{~mm} \mathrm{Hg}$ ), showing positive endothelium-dependent relaxation. Note the absence of cyclical vasospasm in the latter, thus confirming the preservation of endothelial function.

all 3 contractile agonists. This loss of contractility most likely occurs at a more fundamental structural level than just the disruption of either voltage- or receptor-mediated channels, as was seen in excessively distended long saphenous vein (LSV) and ITA grafts. ${ }^{2,6}$ Electron microscopy on LSV subjected to suprasystemic pressure confirmed massive disruption of the intima and media, consisting of endothelium denudation and smooth muscle fiber separation. ${ }^{1,3}$ However, the degree of injury was mainly confined to the media, 
with some minor endothelial separation in ITA subjected to suprasystemic pressure distention. ${ }^{2,6}$ It is likely that similar injury with disruption of the contractile elements in the order of $70 \%$ to $80 \%$ was sustained by RA distended to suprasystemic pressures, as evidenced by a loss of $70 \%$ to $80 \%$ in the magnitude of contraction.

Endothelium-dependent and endothelium-independent relaxation were also reduced in this group, and this indicates endothelium and smooth muscle media disruption. Cooper and Locke ${ }^{2}$ and Cooper and associates ${ }^{6}$ reported a similar reduction of endothelium-dependent relaxation in ITA distended above yield pressure, and this was due to disruption of endothelium continuity. This disruption of the endothelium resulted in a reduction of its capacity to produce nitric oxide from L-arginine under basal conditions or in response to stimuli. ${ }^{21}$ The diffusion of acetylcholine through tears in the endothelium may have caused the cyclical vasospasm seen in this group, possibly through the action of acetylcholine on the smooth muscle media, as shown in Figure 3, A. Such cyclical vasospasm is alarming and may contribute to early graft occlusion.

Furthermore, tears in the endothelium may predispose the underlying torn smooth muscle media to systemic vasoactive factors such as epinephrine, norepinephrine, thromboxane $\mathrm{A}_{2}$, or serotonin, hence increasing their propensity to vasospasm. This was reflected by the increase in sensitivity (reduced $\mathrm{EC}_{50}$ ) of suprasystemic pressure-distended RA rings to all 3 agonists. Exposure of the underlying thrombogenic subintimal layer to growth factors may stimulate medial smooth muscle cell migration and intimal proliferation, ultimately leading to atherosclerosis formation, as was seen in LSV grafts. ${ }^{1,3}$

Physiologic distention with pressure less than yield pressure (mean, $206 \pm 6 \mathrm{~mm} \mathrm{Hg}$ ) did not seem to significantly affect the overall contractility to potassium. However, receptor-mediated contractility to both norepinephrine and serotonin was significantly reduced compared with control rings. We concluded that as the distention pressure increased, the receptor-mediated contraction was first disrupted, possibly through endothelial disruption. Serotonin receptors were affected the most because at higher concentrations of norepinephrine, the contraction achieved in physiologic pressure-distended rings was significantly higher than that in suprasystemic pressure-distended rings. Ultimately, when yield pressure was reached, the smooth muscle fibers were torn apart, and this further reduced their contractility. The disruption of receptor-mediated contraction in the physiologic pressure-distended group of RA may be advantageous in reducing the severity of vasospasm in the graft early after surgery caused by circulating norepinephrine or serotonin.

With physiologic distention, the degree of endothelial disruption was less, as indicated by a loss of endothelium- dependent relaxation of only $30 \%$, than with control. Unlike with suprasystemic pressure distention, cyclical vasospasm on exposure to acetylcholine concentrations more than $10^{-6}$ $\mathrm{mol} / \mathrm{L}$ was not observed in this group of RA; this suggests that endothelial disruption is less with physiologic pressure distention. Manasse and colleagues ${ }^{20}$ also reported no adverse effects of gentle hydrostatic distention $(80 \mathrm{~mm} \mathrm{Hg})$ in RA grafts, with a slightly better early patency rate compared with undistended RA grafts.

Because the main injury associated with distention in arterial grafts was reported to be in the media, endotheliumindependent relaxation to nitroprusside was significantly reduced in both distended groups. This varied with the degree of distention. ${ }^{2,6}$

In conclusion, hydrostatic distention of coronary conduits has a cumulative effect on vasoreactivity, depending on the degree of pressure applied. Physiologic pressure distention seems to have a selective effect on receptormediated contraction while preserving contraction to potassium chloride. This may reflect mild endothelial injury from hydrostatic distention, because endothelium-dependent relaxation was preserved at physiologic concentrations of acetylcholine. This may be beneficial in the first 48 hours after bypass surgery by reducing vasospasm in RA grafts caused by circulating norepinephrine and serotonin. Suprasystemic pressure distention, however, greatly reduces vasoreactivity and endothelial relaxation, which might be due to severe endothelial and smooth muscle medial disruption. Because of the damaging effects on vascular relaxation, distention of RA grafts to suprasystemic pressure should be avoided.

\section{References}

1. Hausmann H, Merker HJ, Hetzer R. Pressure controlled preparation of the saphenous vein with papaverine for aortocoronary venous bypass. J Card Surg. 1996;11:155-62.

2. Cooper GJ, Locke TJ. Distension reduces the vasoreactivity of the internal mammary artery. Eur J Cardiothorac Surg. 1996;10:26-31.

3. Chester AH, Buttery LD, Borland JA, Springall DR, Rothery S, Severs NJ, et al. Structural, biochemical and functional effects of distending pressure in the human saphenous vein: implications for bypass grafting. Coron Artery Dis. 1998;9:143-51.

4. Carpentier A, Guermonprez JL, Deloche A, Frechette C, DuBost C. The aorta-to-coronary radial artery bypass graft. A technique avoiding pathological changes in grafts. Ann Thorac Surg. 1973;16:111-21.

5. Acar C, Jebara V, Portoghese M, Beyssen B, Pahny JY, Grare P, et al. Revival of the radial artery for coronary artery bypass grafting. Ann Thorac Surg. 1992;54:652-9.

6. Cooper GJ, Gillot T, Francis SE, Angelini GD. Distension produces medial but not endothelial damage in porcine internal mammary artery. Cardiovasc Surg. 1995;3:171-4.

7. van Son JA, Smedts F, Vincent JG, van Lier HJ, Kubat K. Comparative anatomic studies of various arterial conduits for myocardial revascularization. J Thorac Cardiovasc Surg. 1990;99:703-7.

8. Reyes AT, Frame R, Brodman RF. Technique for harvesting the radial artery as a coronary artery bypass graft. Ann Thorac Surg. 1995;59: 118-26.

9. Chong WC, Ong PJ, Hayward C, Moat N, Collins P. Effects of storage solutions on in vitro vasoreactivity of radial artery conduits. $J$ Thorac Cardiovasc Surg. 2001;122:470-5. 
10. Dobrin PB. Mechanical properties of arteries. Physiol Rev. 1978;58: 397-460.

11. Borger MA, Cohen G, Buth KJ, Rao V, Bozinovski J, Liaghati-Nasseri $\mathrm{N}$, et al. Multiple arterial grafts. Radial versus right internal thoracic arteries. Circulation. 1998;98(Suppl):II7-13.

12. He GW, Yang CQ. Use of verapamil and nitroglycerin solution in preparation of radial artery for coronary grafting. Ann Thorac Surg. 1996;61:610-4.

13. He GW. Verapamil plus nitroglycerin solution maximally preserves endothelial function of the radial artery: comparison with papaverine solution. J Thorac Cardiovasc Surg. 1998;115:1321-7.

14. Dietl CA, Benoit CH. Radial artery graft for coronary revascularization: technical considerations. Ann Thorac Surg. 1995;60:102-9.

15. Affonso da Costa FD, Affonso da Costa I, Poffo R, Abuchaim D, Gaspar R, Garcia L, et al. Myocardial revascularization with the radial artery. A clinical and angiographic study. Ann Thorac Surg. 1996;62: 475-80.

16. Shapira OM, Alkon JD, Aldea GS, Madera F, Lazar HL, Shemin RJ.
Clinical outcomes in patients undergoing coronary artery bypass grafting with preferred use of the radial artery. J Card Surg. 1997;12:381-8.

17. Tatoulis J, Buxton BF, Fuller JA. Bilateral radial artery grafts in coronary reconstruction: technique and early results in 261 patients. Ann Thorac Surg. 1998;66:714-9.

18. Royse AG, Royse CF, Shah P, Williams A, Kaushik S, Tatoulis J. Radial artery harvest technique, use and functional outcome. Eur J Cardiothorac Surg. 1999;15:186-93.

19. Dipp MA, Nye PC, Taggart DP. Phenoxybenzamine is more effective and less harmful than papaverine in the prevention of radial artery vasospasm. Eur J Cardiothorac Surg. 2001;19:482-6.

20. Manasse E, Sperti G, Suma H, Canosa C, Kol A, Martinelli L, et al. Use of the radial artery for myocardial revascularization. Ann Thorac Surg. 1996;62:1076-82.

21. Angelini GD, Christie MI, Bryan AJ, Lewis MJ. Surgical preparation impairs release of endothelium-derived relaxing factor from human saphenous vein. Ann Thorac Surg. 1989;48:417-20.

\section{Availability of Journal back issues}

As a service to our subscribers, copies of back issues of The Journal of Thoracic and Cardiovascular Surgery for the preceding 5 years are maintained and are available for purchase from Elsevier Inc. until inventory is depleted. Please write to Elsevier Inc., Subscription Customer Service, 6277 Sea Harbor Dr, Orlando, FL 32877, or call $800-654-2452$ or $407-345-4000$ for information on availability of particular issues and prices. 